\title{
Ability of Curcuminoid from Curcuma domestica Val. in Reducing the Secretion of Reactive Oxygen Intermediates by Synovial Fluid Monocytes in Patients with Osteoarthritis
}

\author{
Nyoman Kertia ${ }^{1,2^{*}}$, Ahmad Husain Asdie ${ }^{1,2}$, Wasilah Rochmah ${ }^{1,2}$, and Marsetyawan ${ }^{3}$
}

\author{
${ }^{1}$ Department of Internal Medicine, Faculty of Medicine, Universitas Gadjah Mada, Yogyakarta, \\ Indonesia \\ ${ }^{2}$ Department of Internal Medicine, Dr Sardjito Hospital, Yogyakarta, Indonesia \\ ${ }^{3}$ Department of Histology and Cell Biology, Faculty of Medicine, Universitas Gadjah Mada, Yogyakarta, \\ Indonesia
}

\begin{abstract}
Increasing the secretion of reactive oxygen intermediates (ROI) by monocytes in the synovial fluid is an indicator to determine the severity of joint inflammation. Previous studies have shown that curcumin inhibit the osteoarthritis progression with its ability to inhibite the activity of the nitric oxide synthase (NOS) enzyme from macrophages. In this prospective randomized open end blinded evaluations = PROBE study, 80 patients with knee osteoarthritis were eligable. The subject were devided in to two group: group who received $3 \times 30$ $\mathrm{mg}$ of curcuminoid from Curcuma domestica Val. extract (curcuminoid group) and group who received $3 \times 25$ $\mathrm{mg}$ of diclofenac sodium (diclofenac group) as comparison. The treatment was for 4 weeks time. The secretion of ROI by sinovial fluid monocytes was calculated by scoring the amount of formazan formation after neutral red staining in nitrobleu tetrazolium reduction assay. The result of this study showed that the secretion of ROI by synovial fluid monocytes was significantly decreased in both groups $(p<0.001)$ respectively. There was no significant difference in decreasing of ROI secretion of synovial fluid monocytes between both treatment groups $(\mathrm{p}=0.92)$.
\end{abstract}

Keywords : curcuminoid, diclofenac sodium, reactive oxygen intermediates, monocyte, osteoarthritis

\section{Introduction}

Osteoarthritis (OA) is the most often joint disease found in people. The disease is a major cause of musculoskeletal disorders throughout the world and become the sec largest cause of physical disability after ischemic heart disease for over 50 years of age. This disease causes loss of working $h$ and high cost of treatment (Dieppe, 2008). The prevalence of OA increases with increasing of age (Breedveld, 2004).

\section{"Corresponding author:}

Nyoman Kertia

Department of Internal Medicine, Faculty of Medicine, Universitas Gadjah Mada, Yogyakarta, Indonesia

Email : nyomankertia@yahoo.com
Pathophysiology of OA is mixed between the process of degeneration and inflammation, it is evidenced by the degeneration of cartilage which is accompanied by an increase in leukocyte count and pro-inflammatory cytokines in synovial fluid of affected joints (Ratiner et al., 2001). In OA there is imbalance between synthesis and degradation of joint cartilage, and subchondral bone. Joint degradation is initiated by mechanical loading which resulting in chondrocyte metabolism disorders, production of proteolytic enzymes such as matrix metalloproteinase (MMP) and damage of joint cartilage. The occurrence of multiple microfractur cause degradation and depletion of vulnerable joints, changes in joint architecture and the formation of osteophyte. 
If it happen, the osteoarthritis progression will continue. Changes in architecture of the joint resulting in joint mechanics change that cause increase pressure on the joints, further joint damage, release of damage enzymes and inflammation of the joints (Berenbaum, 2008). In the elimination process of foreign antigens or when interacting with stimuli such as cytokines, the oxidative burst of monocytes showed an increased capacity to produce ROI in large quantities. Reactive oxygen intermediates play an important role in the process of inflammation and tissue damage (Felson, 2008)

The study of anti-inflammatory activity of curcumin has been done. Curcumin one component of curcuminoid has more powerful anti-inflammatory activity than the other components (Parslow \& Bainton, 2003). In vitro curcumin inhibite the activity of phospholypase, lypoxigenase, cycloxigenase-2 (COX-2), leucotrien, prostaglandin, thromboxane, Nitric Oxide, collagenase, elastase, hyaluronidase, interferon, TNF-a and IL-12. In people with rheumatoid arthritis, curcumin reduces the stiffness, swollen joints and walking time. Curcumin also suppressed the postoperative inflammation (Joe et al., 2004). Secretion of ROI by monocytes in the synovial fluid determine the severity of joint inflammation. Two important mediators produced by monocytes in the synovial fluid in initiate the inflammatory process and elimination of antigen are COX-2 enzyme and reactive oxygen intermediates (ROI). Increasing of ROI secretion by monocytes in the synovial fluid will follow by increasing of joint inflammation (Chainani, 2003). Production of nitric oxide and oxygen radicals in chondrocytes are affected by the biological process of osteoarthritis and rheumatoid arthritis (Mazzetti et al., 2001). The results of previous studies have shown that curcumin inhibits the osteoarthritis process (Ukil et al., 2003).

This study aim to assess the ability of curcuminoid from Curcuma domestica Val. rhyzome extract in inhibit the ROI secretion of synovial fluid monocytes in osteoarthritis.

\section{Materials and Methods \\ Research design}

This is a prospective randomized open end blinded evaluation (PROBE) study.

\section{Materials}

Extraction was done by sorted the Curcuma domestica Val. rhyzome then washed, cut into pieces with a thickness of 1-2 $\mathrm{mm}$ and dried with drying cupboard for 24 $\mathrm{h}$ at $40{ }^{\circ} \mathrm{C}$ to obtain maximum water content of $10 \% \mathrm{v} / \mathrm{w}$. After dry it was made to be some powder. The powder was mixed with ethanol and then macerated (soaked) for 24 $\mathrm{h}$, then filtered with a Buchner funnel (with vacuum pressure). Collected filtrate was evaporated at $45^{\circ} \mathrm{C}$ in vacuum condition. For the determination of curcuminoids curcumin standard solution used with varying degrees of concentration. Extract obtained was diluted to $100 \mathrm{mg} / \mathrm{mL}$ and touched on silica gel GF 254 plates and then eluted with a mobile phase system chloroform-methanol (97-3) $\mathrm{v} / \mathrm{w}$. Detection of spots is done by ultraviolet light $254 \mathrm{~nm}$ and $365 \mathrm{~nm}$. The scan was then performed by Thin Layer Chromatography scanner. The level of curcumin, desmetoxi curcumin and bisdesmetoxi curcumin as components of curcuminoids was calculated by linear regression method. The extract was entered in the capsuls which the dose of 30 $\mathrm{mg}$ curcuminoid. The other capsules contain $25 \mathrm{mg}$ of sodium diclofenac.

\section{Research subjects}

This study was run at the Rheumatology Clinic, Department of Internal Medicine Faculty of Medicine, Universitas Gadjah Mada/Dr. Sardjito Hospital - Yogyakarta. The study population were patients with knee OA, registered and were still controlled in Dr. Sardjito General Hospital. Random selection was done among 168 patients to find 80 patients who eligible in this research. The subjects have no arthritis other than osteoarthritis, had 
no abnormalities of liver, kidney or bone marrow function, did not have any history of gastritis, peptic or duodenal ulcer, no history of hypersensitivity to diclofenac sodium and curcuminoid, did not use anti-coagulant medication or other anti-inflammatory drugs, and agree to follow the study with signed the informed consent.

After 1 week washed-out, the random assignment was done so that the sample was divided into treatment groups and control groups. The treatment was for 4 weeks period. The treatment group were given $3 \times 30 \mathrm{mg}$ curcuminoid from Curcuma Val. rhyzome extract, while the control group were given $3 \times 25 \mathrm{mg}$ diclofenac sodium. Assessment of the treatment results was performed before and after 4 weeks treatment by scoring the formazan sedimentation in the cytoplasm of monocytes. Data analysis was conducted on the amount of ROI secretion by synovial fluid monocytes before and after treatment.

\section{Laboratory examination}

Before starting the treatment, $2 \mathrm{~mL}$ of synovial fluid was taken from the affected knee. The culture of monocytes by PMA stimulation was performed. By nitroblue tetrazolium (NBT) reduction assay, the formazan sedimentation was able to assess. Since the formazan is the end result of the reaction between the NBT and ROI, the amount of ROI secretion by synovial fluid monocytes were calculated by scoring the formazan sedimentation in the cytoplasm of monocytes. Monocytes culture was added by $500 \mathrm{ul}$ NBT solution containing $125 \mathrm{ng} / \mathrm{mL}$ PMA and incubated at $37^{\circ} \mathrm{C}$ and $5 \% \mathrm{CO}_{2}$ for $60 \mathrm{~min}$. Cells was then washed 3 times with PBS, dried at room temperature and fixed in absolute methanol for $30 \mathrm{sec}$ and painted with neutral red solution for $15 \mathrm{~min}$ and then washed with distilled water then dried at room temperature and ready to be observed. The cytoplasm of monocytes without secreted ROI was pale, while that secreted ROI looks blue insoluble formazan sedimentation as a result of ROI and NBT reaction. Based on the amount of formazan sedimentation the monocytes were differentiated into 4 groups. Without secreted ROI (no formazan deposits in the cytoplasm, given the value 0 ), which secreted a littleamount of ROI (maximum formazan sedimentation reaches a quarter of the cytoplasm, given the value 1), which secreted ROI in large quantities (formazan sedimentation between a quarter to three-quarter of the cytoplasm, given the value 2 ) and which secreted ROI in a very large quantities (more than three-quarter formazan sedimentation of the cytoplasm, given the value 3) (Figure 1).

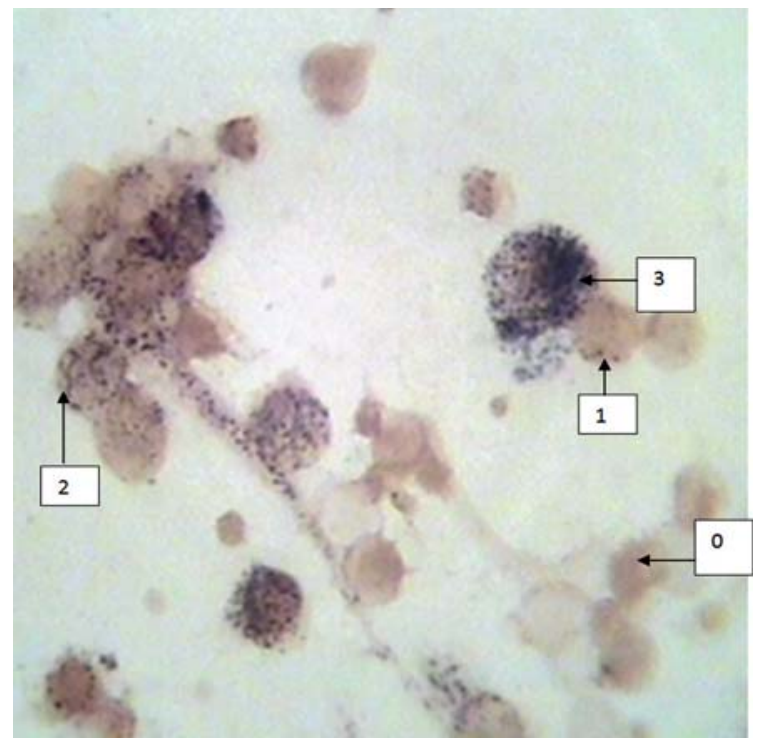

Figure 1. Secretion of ROI by synovial fluid monocytes

Before the study started, firstly the researchers test the value of kappa to determine intraobserver and interobserver consistency of the ROI value secreted by monocytes in the synovial fluid. Observation was done by two assessor. Each assessor observed 40 monocytes then calculated the value of intraobserver and interobserver consistency. In assessing the effectiveness of the treatments each assessor observed 100 monocytes in each preparate before starting the treatmen and after 4 weeks treatment.

\section{Statistical analysis}

Unpaired Student's - t test was performed for analysis. 


\section{Results and Discussions}

A total of 80 patients with knee osteoarthritis were eligible and willing to participate in this study. Subjects were divided randomly into two groups: the treatment group (named curcuminoid group) were given $3 x$ $30 \mathrm{mg}$ curcuminoid from Curcuma domestica Val. rhyzome extract, while the control group (named diclofenac group) were given $3 \times 25 \mathrm{mg}$ diclofenac sodium.

In curcuminoid group number of subjects who participated in the study were 39 patients consisting of 15 men and 24 women. The mean age was $64.05 \pm 8.83$ years. The duration suffering of osteoarthritis was $41.23 \pm 32.60$ months. The body mass index was $26.28 \pm$ $3.62 \mathrm{~kg} / \mathrm{m}^{2}$. Five subjects were excluded from the study with the reasons: 1 Subject drank piroxicam, 1 subject experienced ureter colic due to urinary tract stones, 1 subject had hematuria due to tumor of vesica urinaria, 1 subject stopped the curcuminoid treatment as his family request and 1 subject experienced an acute exacerbation of chronic obstructive pulmonary disease. Number of subjects in the curcuminoid group who finished the study was 34 patients, comprising 11 men and 23 women.

In diclofenac group the number of subjects who participated in the study were 41 patients consisting of 12 men and 29 women. The mean age was $64.56 \pm 8.86$ years. The duration suffering of osteoarthritis was $40.37 \pm 30.87$ months. The body mass index was $26.44 \pm 4.79 \mathrm{~kg} / \mathrm{m}^{2}$. Two subjects were excluded from the study with the reasons: 1 subject experiencing dyspepsia on the seventh day of treatment which did not improve by giving omeprazole $10 \mathrm{mg} 1$ tablet daily and 1 subject has no synovial fluid in aspiration.
Number of subjects in the diclofenac group who finished the study was 39 patients, comprising 11 men and 28 women.

ROI secretion by monocytes before treatment were $2.25 \pm 0.23$ in the curcuminoid group while $2.20 \pm 0.21$ in diclofenac group. Reactive oxygen intermediates play an important role in the process of inflammation and tissue damage. Exposure of ROI to normal cells will cause a variety of pathological changes leading to cell and tissue damage for example in pathogenesis of osteoarthritis (Ahmed et al., 2005; Shah et al., 2005). Monocytes from patients with rheumatoid arthritis release increase amount of reactive oxygen intermediates. Reactive oxygen intermediates play an important role in the process of cartilage degradation in the pathogenesis of some rheumatic diseases through lipid peroxidation in chondrocytes (Arora et al., 2000). In this study the ROI secretion by synovial fluid monocytes was not significantly different between the two groups $(p=0.16)$.

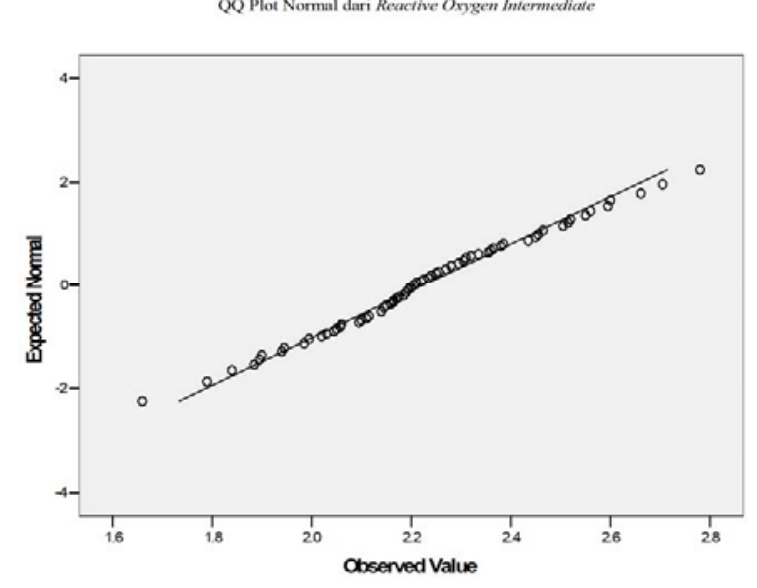

Figure 2. Distribution of ROI secretion by Monocytes, $\mathrm{p}=\mathbf{0 . 2 0 0}$

Table 1. ROI Secretion by Monocytes Before Treatment

\begin{tabular}{lccccc}
\hline \multirow{2}{*}{ Variable } & \multicolumn{2}{c}{ Mean \pm Curcuminoids } & & \multicolumn{2}{c}{ CI 95\% } \\
\cline { 2 - 3 } & $(\mathrm{n}=39)$ & $\begin{array}{c}\text { Diclofenac } \\
(\mathrm{n}=41)\end{array}$ & P value & Lower & Upper \\
\hline ROI secretion & $2,25 \pm 0,23$ & $2,20 \pm 0,21$ & $0,16^{*}$ & $-0,047$ & 0,147 \\
Description: *Independent t-test & & & & \\
\hline
\end{tabular}


Table 2. ROI Secretion by Monocytes Before and After Treatment

\begin{tabular}{|c|c|c|c|c|c|c|c|c|c|c|}
\hline \multirow[t]{2}{*}{ Variabel } & \multicolumn{2}{|c|}{$\begin{array}{l}\text { Curcuminoid } \\
(\text { Mean } \pm S D)\end{array}$} & \multirow[t]{2}{*}{$P$ value } & \multicolumn{2}{|c|}{ CI 95\% } & \multicolumn{2}{|c|}{$\begin{array}{l}\text { Diclofenac } \\
(\text { Mean } \pm S D)\end{array}$} & \multirow[t]{2}{*}{$P$ value } & \multicolumn{2}{|c|}{ CI 95\% } \\
\hline & Before & After & & Lower & Upper & Before & After & & Lower & Upper \\
\hline $\begin{array}{l}\text { ROI } \\
\text { secretion } \\
\text { Descriptior }\end{array}$ & $\begin{array}{l}2.23 \pm 0.22 \\
: \text { *Indepen }\end{array}$ & $\begin{array}{l}0.76 \pm 0.30 \\
\text { ent } t \text {-test }\end{array}$ & $<0.001^{*}$ & 1.37 & 1.57 & $2.21 \pm 0.20$ & $0.75 \pm 0.32$ & $<0.001$ & 1.32 & 1.59 \\
\hline
\end{tabular}

The distribution of ROI secretion by monocytes before treatment spread follow a normal curve with $p=0.200$ (Figure 2). To analyze the differences of ROI secretion between both group the independent $t$ - test was used, because subjects in curcuminoid group were not same to the subjects in diclofenac group.

ROI secretion by synovial fluid monocytes was significantly decreased in both groups with $\mathrm{p}<0.001$ respectively (Table 2 ). Oxidative stress stimulate the peroxidation of lipid membranes and able to cause a serious cells damage. Changes in biological condition of the cell membranes will increase tissue permeability and disrupt the normal function of these cells. Reactive oxygen intermediates is one of the oxidative markers could be detected in the laboratory (Tiku et al., 2000)

In elimination process of the foreign antigens or when interacting with stimuli such as cytokines, the oxidative burst of monocytes showed an increased capacity to produce ROI in large quantities (Donne et al., 2006). Reactive oxygen intermediates play a role in the process of inflammation and tissue damage in osteoarthritis (Shahet al., 2005). In experimental animals curcumin suppress the production of Nitrite Oxyde (NO) and superoxide anions $\left(\mathrm{O}_{2}{ }^{-}\right)$. There are differential roles of nitric oxide and oxygen radicals in chondrocytes affected by osteoarthritis and rheumatoid arthritis (Mazzetti et al., 2001). Curcumin inhibits the in vitro secretion of ROI by gum fibroblasts and human submandibular gland carcinoma cells (Atsumi et al., 2005). Curcumin Inhibits ROS Formation and Apoptosis in Methylglyoxal-Treated Human Hepatoma G2 Cells (Chan et al., 2005). The results of this study indicate that there was no significant difference in decreasing of ROI secretion by synovial fluid monocytes during treatment between the two groups (Table $3)$. The ability of both drugs did not differ

Table 3. Change of ROI secretion in both groups

\begin{tabular}{lccccc}
\hline \multirow{2}{*}{ Variable } & \multicolumn{2}{c}{ Mean \pm SD } & & \multicolumn{2}{c}{ CI 95\% } \\
\cline { 2 - 3 } \cline { 5 - 6 } & $\begin{array}{c}\text { Curcuminoid } \\
(\mathrm{n}=34)\end{array}$ & $\begin{array}{c}\text { Diclofenac } \\
(\mathrm{n}=39)\end{array}$ & P value & Lower & Upper \\
\hline Change of ROI secretion & $\begin{array}{c}1.48 \pm 0.44 \\
\text { Description: \#Mann Whitney U test }\end{array}$ & $1.46 \pm 0.42$ & $0.92 \#$ & -0.19 & 0.21 \\
\hline
\end{tabular}

Table 4. Value of number needed to be treated in both groups

\begin{tabular}{|c|c|c|c|c|c|}
\hline Therapeutic Effect & $\begin{array}{l}\text { Control Event } \\
\text { Rate/CER } \\
\text { (Diclofenac) } \\
\end{array}$ & $\begin{array}{c}\text { Experimental } \\
\text { Event Rate/EER } \\
\text { (Curcuminoid) }\end{array}$ & RRR & ARR & NNT \\
\hline $\begin{array}{l}\text { Decreased secretion of } \\
\text { ROI } \\
(\text { Target scores }<1) \\
\text { RRR = Relative risk red } \\
\text { ARR = Absolute risk re } \\
\text { NNT = Number neede }\end{array}$ & $\begin{array}{c}82.1 \% \\
\text { on }=\mid \text { CER-EER } \\
\text { tion }=\mid \text { CER-EE } \\
\text { be treated }=1 /\end{array}$ & $\begin{array}{l}\text { CER } \\
\text { R }\end{array}$ & $14.0 \%$ & $11.5 \%$ & 9 \\
\hline
\end{tabular}


significantly in reducing the secretion of ROI by monocytes synovial fluid of patients with knee osteoarthritis. It is remains to be further investigated how the mechanism of action of diclofenac sodium and curcuminoid from Curcuma domestica Val. rhyzome extract in suppressing the secretion of ROI by synovial fluid monocytes.

The number needed to be treated analysis of the secretion of ROI by synovial fluid monocytes get that to obtain one subject with decreasing of ROI secretion with the target score of less than 1 in the group that received diclofenac sodium compared to curcuminoid from Curcuma domestica Val. rhyzome extract, the number of subjects needed to be treated are 9 patients (Table 4).

Oraly treatment by curcuminoid from Curcuma domestica Val. rhyzome extract significantly inhibite the secretion of ROI by monocytes synovial fluid of osteoarthritic joint. The ability of curcuminoid from Curcuma domestica Val. rhyzome extract in inhibite the secretion of ROI by monocytes synovial fluid is not significantly different compared to diclofenac sodium.

\section{Acknowledgements}

The author wishes to express sincere gratitude to dr. Sri Endarini $\mathrm{MpH}$ the director of Dr. Sardjito General Hospital for her exellent support and advice for this research.

\section{References}

Ahmed, S., Anuntiyo, J., Malemud, C. J., Haqqi, T. M., 2005 Biological Basis for the Use of Botanicals in Osteoarthritis and Rheumatoid Arthritis: A Review. Comp. Alt. Med., 2, 301-308.

Arora, M., Arora, R., Kumar, A., Das, N., Srivastava, L. M., 2000 Monocyte from Patients with Rheumatoid Arthritis Release Increase Amount of Reactive Oxygen Intermediates. Curr. Sci., 78(8), 989-991.

Atsumi, T., Fujisawa, S., Tonosaki, K., 2005 Relationship Between Intracellular ROS
Production and Membrane Mobility in Curcumin and Tetrahydrocurcumin Treated Human Gingival Fibroblast and Human Submandibular Gland Carcinoma Cells. Oral Dis., 11, 236242.

Berenbaum, F.,2008 Osteoarthritis: Pathology and Pathogenesis in Klippel, J. H., Stone, J. H., Crofford, L. J., White, P. H. (eds) Primer on The Rheumatic Diseases, $13^{\text {th }}$ ed, pp. 229-34. Arthritis Foundation, New York.

Breedveld, F. C., 2004 Osteoarthritis the Impact of a Serious Disease. J. Rheumatol., 43(1), 14-18

Chainani, N., 2003 Safety and Antiinflammatory Activity of Curcumin: A Component of Turmeric (Curcuma longa). J. Compl. Med., 9(1), 161-168.

Chan, W. H., Wu, H. J., Hsuuw, Y. D., 2005 Curcumin Inhibits ROS Formation and Apoptosis in Methylglyoxal-Treated Human Hepatoma G2 Cells. Ann. N.Y. Acad. Sci., 1042, 372-378.

Dieppe, P.A., 2008 Osteoarthritis: Clinical Feature in Klippel, J. H., Stone, J. H., Crofford, L. J., White, P. H. (eds) Primer on The Rheumatic Diseases, $13^{\text {th }}$ ed., pp. 224-28. Arthritis Foundation, New York.

Donne, I. D., Rossi, R., Colombo, R., Giustarini, D., Milzani, A., 2006 Biomarker of Oxidative Damage in Human Diseases. Clin. Chem., 52(4), 601-623.

Felson, D. T., 2008 Osteoarthritis in Fauci, A.S., Braunwald, E. B., Kasper, D. L., Hauser, S. L., Longo, D. L., Jameson, J. L., Loscalzo, J. (eds) Harrison's Principles of Internal Medicine, $17^{\text {th }}$ ed, pp. 2158-65. McGraw-Hill Medical, New York.

Joe, B., Vijaykumar, M., Lokesh, B. R., 2004 Biological Properties of Curcumin, Cellular and Molecular Mechanisms of Action. Critic. Rev. Food Science Nut, 44, 97-111.

Mazzetti, I., Grigolo, B., Pulsatelli, L., Dolzani, P., Silvestri, T., Roseti, L., Meliconi, R., Facchini, A., 2001 Differential roles of nitric oxide and oxygen radicals in 
chondrocytes affected by osteoarthritis and rheumatoid arthritis. Clin. Sci., 101, 593-599.

Parslow, T. G., Bainton, D. F., 2003 Innate Immunity in Parslow, T. G., Stites, D. P., Terr, A. I., Imboden, J. B., (eds) Medical Immunology, pp. 19-39. Mc.Graw Hill, New York.

Ratiner, B., Gramas, D. A., Lane, N. E., 2001 Osteoarthritis in Weisman, M. H., Weintblatt, Louie, J. S. (eds) Treatment of the Rehumatic Diseases, pp. 461-71. W. B. Sauders Company, Philadelphia.

Shah, R., Raska, K., Tiku, M. T., 2005 The Presence of Molecular Marker of Invivo Lipid Peroxidation in Osteoarthritic Cartilage. Arthritis Rheum., 52, 799807.

Tiku, M. L., Shah, R., Allison, G., 2000 Evidence Linking Chondrocyte Lipid Peroxidation to Cartilage Matrix Protein Degradation. J. Biochem., 275, 269-275.

Ukil, A., Maity, S., Karmakar, S., Datta, N., Vedasiromoni, J. R., Pijush., 2003 Curcumin the Major Component of Food Flavour Turmeric Reduces Mucosal Injury in Trinitrobenzene Sulphonic Acid-Induced Colitis. Br. J. Pharmacol.,139, 209-218. 